\title{
Correction to: Cost analysis of laparoscopic appendectomy in a large integrated healthcare system
}

\author{
Lavina Malhotra ${ }^{1}$ - Elizabeth M. Pontarelli ${ }^{1}$. Gary G. Grinberg ${ }^{1} \cdot$ Richard S. Isaacs $^{1}$ - James P. Morris ${ }^{2}$. \\ Pandu R. Yenumula ${ }^{1}$
}

Published online: 22 February 2021

(c) The Author(s), under exclusive licence to Springer Science+Business Media, LLC part of Springer Nature 2021

\section{Correction to: Surgical Endoscopy https://doi.org/10.1007/s00464-020-08266-0}

This article was updated to a correct typo in Figure 3 (the stapler only surgeon count $=205$, not 295 ).

This article was updated to correct the third sentence of the next-to-last paragraph, to read: "The idea of this study was not to account for every dollar but to look at the bigger picture of trend in the cost."

This article was updated to correct the fifth sentence of the next-to-last paragraph of the Discussion section, to read: "Nonetheless, staplers were used in $88 \%$ of cases, and SUDs in $80 \%$ with a distinct correlation to individual surgeons."
Publisher's Note Springer Nature remains neutral with regard to jurisdictional claims in published maps and institutional affiliations.

The original article can be found online at https://doi.org/10.1007/ s00464-020-08266-0.

Pandu R. Yenumula

panduranga.r.yenumula@kp.org

1 Kaiser Permanente South Sacramento, 6600 Bruceville Rd, Sacramento, CA 95823, USA

2 Kaiser Permanente South San Francisco, South San Francisco, CA, USA 